\title{
Lifestyle Risk Factors and Findings on Brain Magnetic Resonance Imaging of Older Adult American Indians: The Strong Heart Study
}

\author{
Dean Shibata $^{a}$ Astrid Suchy-Dicey ${ }^{b}$ Cara L. Carty ${ }^{b, c}$ Tara Madhyastha, ${ }^{a}$ \\ Tauqeer Ali ${ }^{g}$ Lyle Best ${ }^{\text {h }}$ Thomas J. Grabowski Jr. ${ }^{d,}$ e W.T. Longstreth Jr. ${ }^{\text {e, }}{ }^{\text {f }}$ \\ Dedra Buchwald ${ }^{\text {b, }}$ \\ ${ }^{a}$ Department of Radiology, University of Washington, Seattle, WA, USA; ${ }^{b}$ Partnerships for Native Health, Washington \\ State University, Pullman, WA, USA; ' $E$ Elson S Floyd College of Medicine, Washington State University, Seattle, WA, \\ USA; ${ }^{\mathrm{d} I n t e g r a t e d ~ B r a i n ~ I m a g i n g ~ C e n t e r, ~ U n i v e r s i t y ~ o f ~ W a s h i n g t o n, ~ S e a t t l e, ~ W A, ~ U S A ; ~}{ }^{\mathrm{e}}$ Department of Neurology, \\ University of Washington, Seattle, WA, USA; ${ }^{\mathrm{f}}$ Department of Epidemiology, University of Washington, Seattle, \\ WA, USA; ${ }^{9}$ Center for American Indian Health Research, College of Public Health, University of Oklahoma Health \\ Sciences Center, Oklahoma City, OK, USA; ${ }^{\text {h }}$ Strong Heart Study-Dakota Center, Eagle Butte, SD, USA
}

\section{Keywords}

Brain magnetic resonance imaging $\cdot$ Smoking $\cdot$ Alcohol .

Body mass index $\cdot$ American Indian $\cdot$ Infarcts

\begin{abstract}
Background: Clinical stroke is prevalent in American Indians, but the lifestyle risk factors for vascular brain injury have not been well-studied in this population. The purpose of this study was to correlate brain magnetic resonance imaging (MRI) findings with obesity, alcohol use, and smoking behaviors in elderly American Indians from the Strong Heart Study. Methods: Cranial MRI scans $(n=789)$ were analyzed for dichotomous measures of infarcts, hemorrhages, white matter hyperintensities $(\mathrm{WMH})$, and cerebral atrophy and continuous measures of total brain, $\mathrm{WMH}$, and hippocampal volume. Poisson regression was used to estimate prevalence ratios, and linear regression was used to estimate measures of association for continuous outcomes. Models were adjusted for the risk factors of interest as well as age, sex, study site, income, education, hypertension, diabetes, and low-density li-
\end{abstract}

\section{KARGER}

(c) 2019 S. Karger AG, Basel

E-Mail karger@karger.com

www.karger.com/ned poprotein cholesterol. Results: Smoking was associated with increased hippocampal atrophy $(p=0.002)$ and increased prevalence of sulcal widening ( $p<0.001)$. Relative to nonsmokers, smokers with more than 25 pack-years of smoking had a $27 \%$ (95\% Cl 7-47\%) increased prevalence of highgrade sulci, $p=0.005$. Body mass index was inversely associated with prevalence of nonlacunar infarcts and sulcal widening (all $p=0.004$ ). Alcohol use was not significantly associated with any of the measured MRI findings. Conclusions: This study found similar associations between smoking and vascular brain injury among American Indians, as seen in other populations. In particular, these findings support the role of smoking as a key correlate for cerebral atrophy.

(c) 2019 S. Karger AG, Basel

\section{Introduction}

The prevalence of stroke in American Indians as noted in the Strong Heart Study (SHS) nearly twice that of Americans of European descent (5.8 vs. 3.0\%) [1-3]. 
Despite progress in acute stroke diagnosis and treatment, prevention remains the most effective approach to reducing morbidity and mortality. Cranial magnetic resonance imaging (MRI) enables early identification of subclinical or covert vascular brain injury, such as infarcts, hemorrhages, white matter hyperintensities $(\mathrm{WMH})$, and cerebral atrophy $[4,5]$. Prior studies, primarily conducted in populations with European heritage, have found correlation of both overt clinical stroke and these covert MRI findings with obesity, cigarette smoking, and alcohol use [6, 7]. Some recent studies have demonstrated different associations in other populations. For example, worsening WMH has been associated with continued smoking in those of European but not African descent [8]. Similarly, whites may have stronger associations between WMH and alcohol consumption than African Caribbeans [9]. Given the high prevalence of vascular disease and its risk factors in American Indians $[10,11]$, understanding the association between lifestyle risk factors and brain injury is critical. The Cerebrovascular Disease and its Consequences in American Indians (CDCAI) study [12] was undertaken to determine the prevalence and severity of brain abnormalities on brain MRI in this high-risk population and correlate them with risk factors and clinical manifestations. CDCAI involves the surviving members of the SHS cohort of American Indians aged 64 years and older from 3 geographic regions (Northern Plains, Southern Plains, and Southwest) and includes a battery of cognitive, neurological, physical, and laboratory assessments along with cranial MRI scans. The purpose of this study is to extend the prior assessment of vascular risk factors [13] to examine associations of body mass index (BMI), smoking, and alcohol use with brain injury using data acquired from the CDCAI study.

\section{Methods}

\section{Participants and Procedures}

The SHS is a longitudinal, multicommunity cohort study aimed at better understanding cardiovascular disease in American Indians. Between 1989 and 1991, 4,549 American Indians were recruited from 13 tribes in the U.S. Southern Plains, Northern Plains, and Southwest [14]. The CDCAI study is an ancillary study conducted between 2010 and 2013 and focused on vascular brain injury, its risk factors, and clinical manifestations among surviving participants from the original SHS [12]. Human subjects research committees from the communities, tribal councils, Indian Health Service, and partner institutions approved the study procedures, and all participants gave written, informed consent. After data collection was complete, 209 participants who completed cranial MRI scans were removed from analyses because one community withdrew consent to use their data. Ultimately, 789 completed usable MRI scans and were included in these analyses.

\section{MRI Procedures}

As described in detail previously [15], 1.5T MRI scanners used image sequences including axial T1, T2, and T2*-weighted images $[16,17]$. For volumetric analysis, $3 \mathrm{~mm}$ fluid-attenuated inversion recovery (FLAIR) and $1.5 \mathrm{~mm}$ sagittal 3D T1-weighted gradient echo images were also obtained.

Brain infarcts were identified as lesions of a characteristic shape, absence of mass effect, and hyperintensity to gray matter on both T2-weighted and FLAIR images (to distinguish them from perivascular spaces which are hypointense on FLAIR) and were required to $>2 \mathrm{~mm}$ in size on both T2-weighted and FLAIR images. White matter infarcts were distinguished from WMH by their focality and distinct low signal on the T1-weighted and high signal on the FLAIR images. Lesions matching these criteria $<2 \mathrm{~cm}$ in maximum dimension and located in the caudate, lenticular nucleus, internal capsule, thalamus, brainstem, cerebellar white matter, centrum semiovale, or corona radiata regions were defined as "lacunes." The remaining infarcts (either larger or in other territories) were classified as non-lacunes.

Brain hemorrhages were hypointense with "blooming" on gradient echo images. Severity of WMH, sulcal widening, and ventricle enlargement were graded using a 10-point scale, with 0 being the least and 9 the most severe [16]. As in prior analyses [18], a grade of 3 or more was considered abnormal. WMH volume was calculated by segmenting the $3 \mathrm{~mm}$ FLAIR images using the Fuzzy Lesion Extractor technique [19]. Total brain volume was measured used the Freesurfer image analysis suite [20,21]. Hippocampal volume was measured using automated segmentation from the 3D T1-weighted images with FIRST in FSL 5.0 [22] and the ENIGMA1 protocol [23]. Intracranial volume was estimated using the ENIGMA1 protocol for FSL [24].

\section{Covariates and Risk Factors}

Interviews, clinical examination, and blood draws were performed within 1 month of the MRI scans. All models were adjusted for age, gender, study site, education, income, hypertension defined as systolic blood pressure $>140 \mathrm{~mm} \mathrm{Hg}$, diastolic blood pressure $>90 \mathrm{~mm} \mathrm{Hg}$, or use of antihypertensive medications, diabetes defined as fasting glucose $>126 \mathrm{mg} / \mathrm{dL}(7 \mathrm{mmol} / \mathrm{L})$ or use of diabetes medications, and high levels of low density lipoprotein cholesterol (LDL) $>160 \mathrm{mg} / \mathrm{dL}$ or use of lipid-lowering medications. The associations of hypertension, diabetes, and high LDL cholesterol with the MRI findings in this population are the topic of a companion paper [13]. Risk factors of interest comprised BMI in $\mathrm{kg} / \mathrm{m}^{2}$, alcohol use, and lifetime smoking, as defined and categorized in Table 1 . BMI was categorized as nor$\mathrm{mal}=18.5-24.9 \mathrm{~kg} / \mathrm{m}^{2}$; overweight $=25-29.9 \mathrm{~kg} / \mathrm{m}^{2}$; obese $=30+$ $\mathrm{kg} / \mathrm{m}^{2}$ (note: one individual with $\mathrm{BMI}<18.5$ was included in the normal category). Alcohol use was categorized as: never drinker; former drinker: last drink >1 year ago; current light drinker: $<2$ drinks/week; current moderate drinker: 2-14 drinks/week or binge drinking once/year; and current heavy drinker: 14+ drinks/ week or binge drinking 2+ times/year. Smoking was categorized in terms of lifetime pack-years: never smoker; smoker with $<10$ pack-years; smoker with 10 to $>25$ pack-years and smoker with $25+$ pack years. 
Table 1. Selected participant characteristics in the CDCAI study at the time of the MRI examination (2010-2013), $n=789$

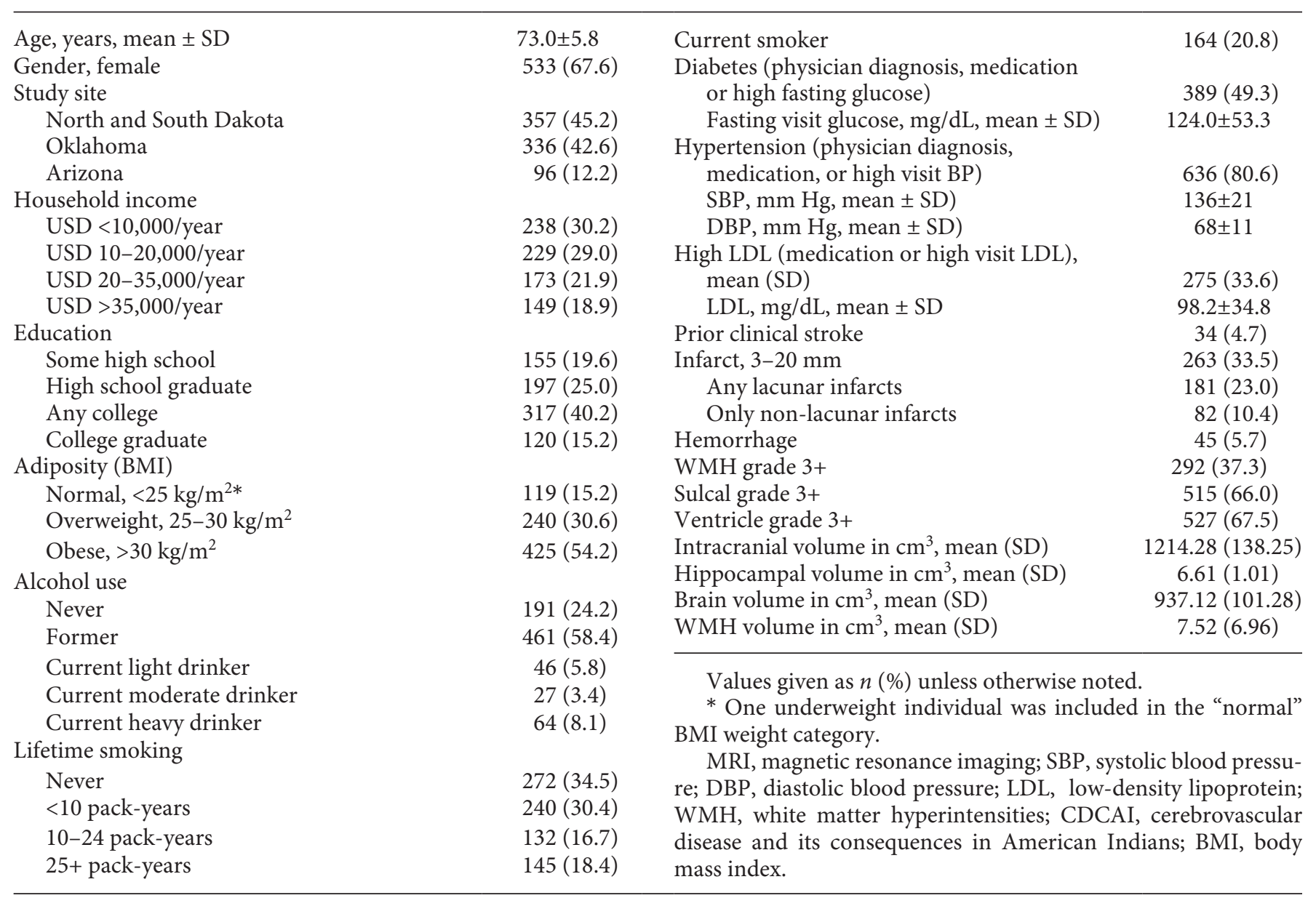

\section{Statistical Procedures}

Participant characteristics were summarized using means and SDs or count and percentages. Poisson regression was used to estimate prevalence ratios (PR) for associations between risk factors and the presence of infarcts or hemorrhages or abnormal grade (grade $\geq 3$ ) for $\mathrm{WMH}$, ventricle enlargement, and sulcal widening. Multivariable linear regression was used to estimate risk factor associations with WMH, hippocampus, or total brain volume, with intracranial volume included as an additional covariate. All models were adjusted for participant age, sex, study site, income, education, diabetes, hypertension, high LDL, and the lifestyle risk factors of interest: smoking, alcohol, and BMI categories. Omnibus Wald tests were used to test the global significance of the categorical risk factor variables; for each risk factor, we tested the null hypothesis that the $\beta$ coefficients for all categories were jointly equal to zero. We used robust sandwich errors estimation to estimate valid standard errors for coefficients in the regression models. Because we examined 10 imaging features and 3 risk factors (30 individual tests), multiple testing is a concern [25]. We adjusted for multiple testing using the false discovery rate (FDR) [26] and set $q=0.05$, which reflects the proportion of false positive significant findings that we are willing to accept. All main results with $p$ values
$<0.0067$, the FDR-corrected critical $p$ value, are indicated with an * and reported as significant. Statistical analyses were conducted using Stata (version 14, Stata Corp., College Station, TX, USA).

\section{Results}

\section{Participants}

Participant characteristics are noted in Table 1 . These elderly adult American Indian participants had a mean age of 73 years and 68\% were women. Over half were obese and had a history of alcohol consumption and cigarette smoking. Vascular risk factors were common with about $80 \%$ of participants having hypertension, almost $50 \%$ having diabetes, and about $40 \%$ having high LDL or use of lipid-lowering medications. Evidence of vascular brain injury on MRI was also common - 33.5\% had infarcts and $37.3 \%$ had abnormal WMH grade. 
Lifestyle Risk Factors and MRI Findings

Lifetime smoking was significantly associated with the presence of sulci-grade $3+, p=0.0007$. Relative to never smokers, smokers with 25 or more pack years had an increased PR of $27 \%(8-48 \%), p=0.005$ (Table 2). Potential effects were observed for even low reported levels of smoking; smokers with $<10$ pack-years also had increased prevalence compared with never smokers, PR (95\% CI) 1.31 (1.15-1.48). Smoking was also associated with hippocampal volume, $p=0.002$, but no other volume measures (Table 3). Relative to never smokers, smokers with 10-24 pack years had slightly reduced hippocampal volume, $\beta(95 \% \mathrm{CI})-0.3(-0.5$ to -0.1$) \mathrm{cm}^{3}$. Interestingly, the reduction was not statistically significant in heavier smokers, though the trend was similar. BMI was inversely associated with the presence of nonlacunar infarcts $(p=$ $0.004)$ and sulci-grade $3+(p=0.004)$. Relative to normal weight individuals, obese individuals had significantly lower risks of these outcomes after adjustment for other lifestyle factors and covariates. No significant associations were observed for alcohol use.

Residuals from linear regression models of WMH were not normally distributed, so in sensitivity analyses, we investigated relationships between risk factors and a binary variable reflecting participants above and below the median WMH volume of $5.95 \mathrm{~cm}^{3}$. Results from these models were also not statistically significant at the FDR significance threshold.

\section{Discussion}

In our population of elderly American Indians, obesity was highly prevalent at $54 \%$, as in other studies of American Indian populations $[27,28]$, and was associated with decreased prevalence of brain abnormalities. Studies assessing obesity as a risk factor for brain atrophy have had variable findings. For example, 2 studies $[29,30]$ found obesity associated with increased risk of silent infarcts, while 3 studies [31-33] found reduced risk of infarcts. Similarly, BMI is positively associated with WMH burden in some studies [34], but negatively associated with WHM burden in others [35-37]. While increased weight loss with cognitive decline in the elderly [37] is a potential explanation for these findings, it is likely that relationships between brain atrophy measures and BMI are complex and may vary by age $[35,38]$, and these effects may also be confounded by survival bias. Furthermore, these relationships may be difficult to interpret from cross-sectional studies, since body weight (or chang-

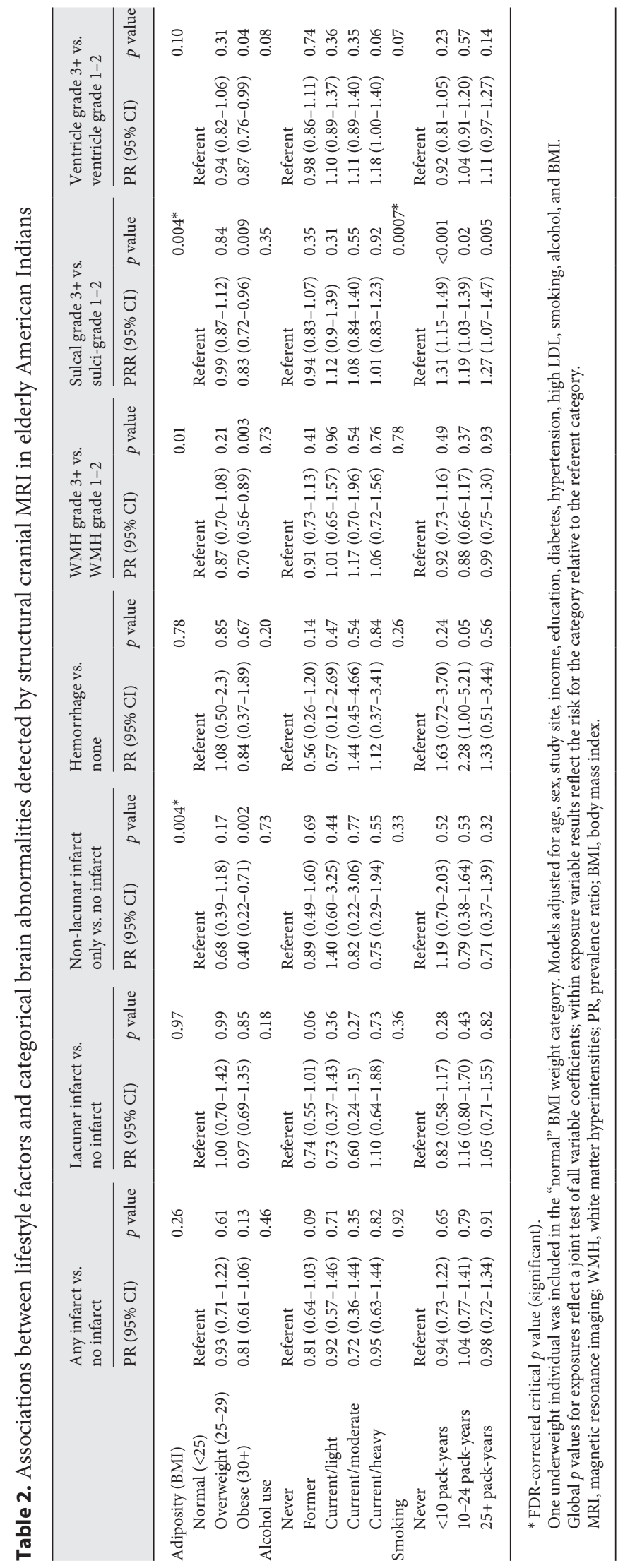

Neuroepidemiology 2019;53:162-168 DOI: $10.1159 / 000501181$
Lifestyle Risk Factors and Findings on Brain MRI of Adult American Indians 
Table 3. Associations between lifestyle factors and volumetric measures from structural cranial MRI in elderly American Indians

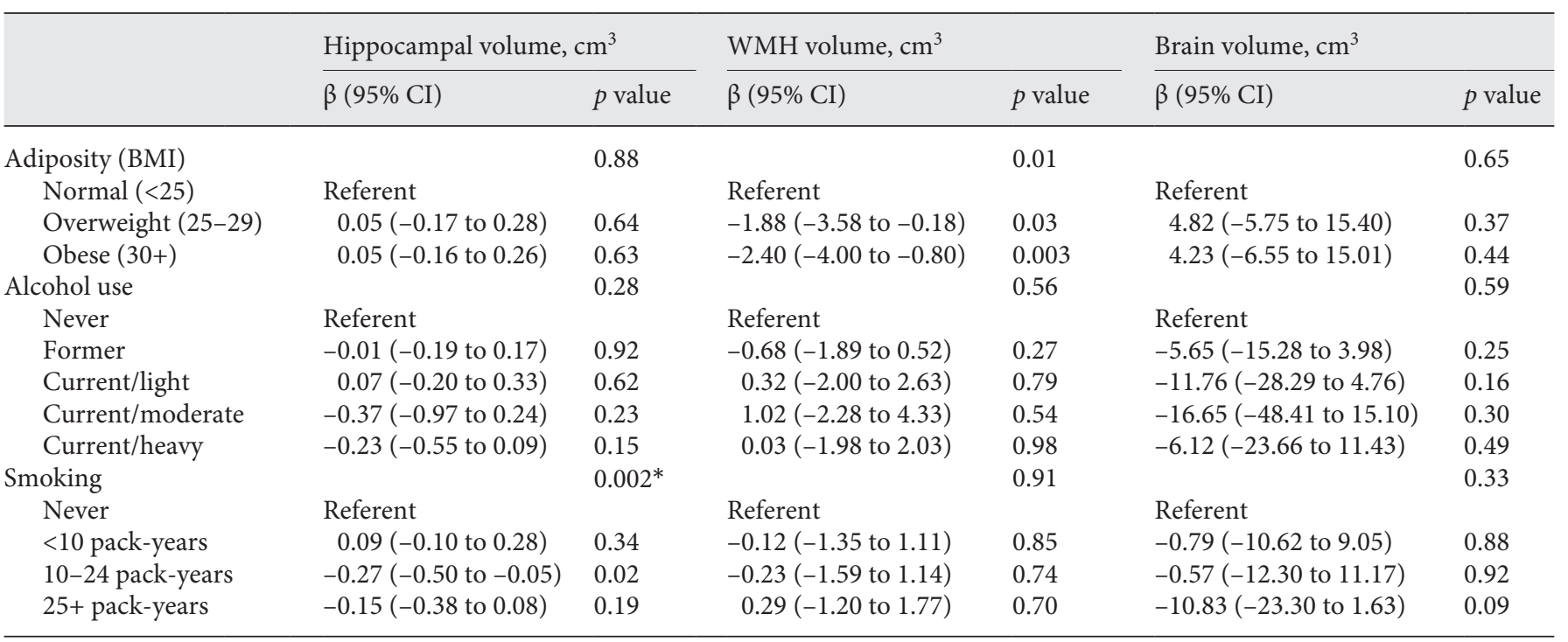

* FDR-corrected critical $p$ value (significant).

One underweight individual was included in the "normal" BMI weight category.

Models adjusted for age, sex, study site, income, education, diabetes, hypertension, high LDL, smoking, alcohol, BMI and IC volume.

Global $p$ values for exposures reflect a joint test of all coefficients; within exposure variable results reflect the mean difference in volume for the category relative to the referent category.

MRI, magnetic resonance imaging; WMH, white matter hyperintensities; BMI, body mass index.

es in weight) may be an early indicator of brain disease, or a potential causal factor [39].

Alcoholism has been reported as being relatively prevalent in the American Indian population [40, 41] yet 12-month alcohol dependence [42] in our population of older adult American Indians was similar to national rates. Only $10.5 \%$ reported having alcohol within the past week. Recent alcohol use (as categorized by use within the past week) was associated with ventricular and sulcal enlargement (measures of cerebral atrophy) and hippocampal volume loss (data not shown) - both findings have been reported in prior studies of European descent [43, 44] and African American [43] populations. Although they likely represent largely chronic changes, these findings may also reflect a component of subacute volume loss from hydration status. Studies in animals suggest that acute alcohol intoxication and recovery causes fluid redistribution in the brain - resulting in rapid ventricular volume changes [45].

Lifetime smoking is relatively prevalent in the study population with $18 \%$ having a $>25$ pack-year history and $17 \%$ reporting a 10-25 pack-year history and represents a major health problem [46] although in our population $41.6 \%$ reported having never smoked. The predominant brain MRI findings associated with smoking in our study were measures of brain atrophy including increased sulci widening and decreased hippocampal volume. These associations have been reported in a number of other studies [8, 47, 48] including African Americans [47] and Asians [47, 49], and animal studies have consistently linked hippocampal neuronal damage to nicotine exposure [48]. The mechanism remains unclear, but may relate to microvascular disease [48].

When compared with similar studies on other populations, these results on an American Indian population demonstrate that although the prevalence of lifestyle-related risk factors may be somewhat higher than other groups, associations with brain abnormalities are relatively similar.

Our study is not without limitations. As discussed, the temporality and causality of associations cannot be examined using these cross-sectional data; however, we discuss their consistency with previously reported relationships in the literature as well as biological plausibility. Although we controlled for clinical vascular risk factors (hypertension, diabetes, and high LDL), there may be residual confounding or measurement error. For example, we had detailed dose information for current drinkers, but not former drinkers. There is also the concern that some of these lifestyle factors may mediate their effects via the clinical 
risk factors and there may be over-controlling in some of our analyses. While lifestyle risk factors hold much promise as being modifiable, our study was unable to address the impact of lifestyle changes with respect to brain injury and aging. Future studies might examine whether interventions for stopping smoking or alcohol use are able to reduce the progression of brain atrophy; for example, one study [50] has found evidence for reversibility of alcohol-related brain atrophy, possibly related to rehydration. The apparent negative association of obesity with the presence of non-lacune infarcts and sulcal widening bears further investigation.

\section{Conclusion}

This is the first large cohort study of older adult American Indian examining lifestyle risk factors for vascular brain injury based upon MRI findings. Indepen- dent of vascular risk factors, smoking was associated with measures of cerebral and hippocampal atrophy. Although similar findings have been reported in other populations, our results underscore the importance of lifestyle factors to reduce the prevalence of vascular brain injury, especially in this high risk, vulnerable population.

\section{Acknowledgments}

None of the authors has any conflicts of interest to report. This work was supported by the National Heart Lung and Blood Institute (grants U01HL41642, U01HL41652, U01HL41654, U01HL65520, U01HL65521, R01HL109315, R01HL109301, R01HL109284, R01HL109282, R01HL109319, and R01HL093086); the National Institute on Aging (grant P50 AG005136); and the Nancy and Buster Alvord Endowment (Thomas J. Montine). The opinions expressed in this manuscript are those of the authors and do not necessarily reflect those of the Indian Health Service (IHS). The authors wish to thank all study communities, participants, and staff.

\section{References}

1 Harris R, Nelson LA, Muller C, Buchwald D. Stroke in American Indians and Alaska Natives: A Systematic Review. Am J Public Health. 2015 Aug;105(8):e16-26.

2 Schieb LJ, Ayala C, Valderrama AL, Veazie MA. Trends and disparities in stroke mortality by region for American Indians and Alaska Natives. Am J Public Health. 2014 Jun; 104(Suppl 3):S368-76.

3 Zhang Y, Galloway JM, Welty TK, Wiebers DO, Whisnant JP, Devereux RB, et al. Incidence and risk factors for stroke in American Indians: the Strong Heart Study. Circulation. 2008 Oct;118(15):1577-84.

4 FriedmanJI, Tang CY, deHaas HJ, Changchien L, Goliasch G, Dabas P, et al. Brain imaging changes associated with risk factors for cardiovascular and cerebrovascular disease in asymptomatic patients. JACC Cardiovasc Imaging. 2014 Oct; 7(10):1039-53.

5 Knopman DS, Penman AD, Catellier DJ, Coker LH, Shibata DK, Sharrett AR, et al. Vascular risk factors and longitudinal changes on brain MRI: the ARIC study. Neurology. 2011 May;76(22):1879-85.

6 Longstreth WT Jr, Dulberg C, Manolio TA Lewis MR, Beauchamp NJ Jr, O'Leary D, et al. Incidence, manifestations, and predictors of brain infarcts defined by serial cranial magnetic resonance imaging in the elderly: the Cardiovascular Health Study. Stroke. 2002 Oct;33(10):2376-82.

7 Vermeer SE, Koudstaal PJ, Oudkerk M, Hofman A, Breteler MM. Prevalence and risk factors of silent brain infarcts in the population- based Rotterdam Scan Study. Stroke. 2002 Jan;33(1):21-5

8 Power MC, Deal JA, Sharrett AR, Jack CR Jr, Knopman D, Mosley TH, et al. Smoking and white matter hyperintensity progression: the ARIC-MRI Study. Neurology. 2015 Feb; 84(8):841-8.

9 Shibata D, Tillin T, Beauchamp N, Heasman J, Hughes AD, Park C, et al. African Caribbeans have greater subclinical cerebrovascular disease than Europeans: this is associated with both their elevated resting and ambulatory blood pressure and their hyperglycaemia. J Hypertens. 2013 Dec;31(12):2391-9.

10 Howard BV. Blood pressure in 13 American Indian communities: the Strong Heart Study. Public Health Rep. 1996;111(Suppl 2):47-8.

11 Lee ET, Howard BV, Go O, Savage PJ, Fabsitz RR, Robbins DC, et al. Prevalence of undiagnosed diabetes in three American Indian populations. A comparison of the 1997 American Diabetes Association diagnostic criteria and the 1985 World Health Organization diagnostic criteria: the Strong Heart Study. Diabetes Care. 2000 Feb;23(2):181-6.

12 Suchy-Dicey AM, Shibata D, Best LG, Verney SP, Longstreth WT Jr, Lee ET, et al. Cranial Magnetic Resonance Imaging in Elderly American Indians: Design, Methods, and Implementation of the Cerebrovascular Disease and Its Consequences in American Indians Study. Neuroepidemiology. 2016;47(2):67-75.

13 Shibata D, Suchy-Dicey A, Carty CL, Madhyastha T, Ali T, Best L, et al. Vascular Risk Factors and Findings on Brain MRI of Elderly
Adult American Indians: The Strong Heart Study. Neuroepidemiology. 2019;52(3-4): 173-80.

14 Sambo BH, Strong Heart Study Investigators. The Strong Heart Study: interaction with and benefit to American Indian communities. Am J Med Sci. 2001 Nov;322(5):282-5.

15 Suchy-Dicey AM, Shibata DK, Madhyastha TM, Grabowski TJ, Longstreth WT Jr, Buchwald DS. Findings of Vascular Brain Injury and Structural Loss from Cranial Magnetic Resonance Imaging in Elderly American Indians: The Strong Heart Study. Neuroepidemiology. 2017;48(1-2):39-47.

16 Manolio TA, Kronmal RA, Burke GL, Poirier V, O'Leary DH, Gardin JM, et al. Magnetic resonance abnormalities and cardiovascular disease in older adults. The Cardiovascular Health Study. Stroke. 1994 Feb;25(2):318-27.

17 Bryan RN, Cai J, Burke G, Hutchinson RG, Liao D, Toole JF, et al. Prevalence and anatomic characteristics of infarct-like lesions on MR images of middle-aged adults: the atherosclerosis risk in communities study. AJNR Am J Neuroradiol. 1999 Aug;20(7):1273-80.

18 Knopman DS, Mosley TH, Catellier DJ, Sharrett AR; Atherosclerosis Risk in Communities (ARIC) Study. Cardiovascular risk factors and cerebral atrophy in a middle-aged cohort. Neurology. 2005 Sep;65(6):876-81.

19 Gibson E, Gao F, Black SE, Lobaugh NJ. Automatic segmentation of white matter hyperintensities in the elderly using FLAIR images at 3T. J Magn Reson Imaging. 2010 Jun;31(6): 1311-22. 
20 Dale AM, Fischl B, Sereno MI. Cortical surface-based analysis. I. Segmentation and surface reconstruction. Neuroimage. 1999 Feb; 9(2):179-94.

21 Fischl B, Sereno MI, Dale AM. Cortical surface-based analysis. II: Inflation, flattening, and a surface-based coordinate system. Neuroimage. 1999 Feb;9(2):195-207.

22 Patenaude B, Smith SM, Kennedy DN, Jenkinson M. A Bayesian model of shape and appearance for subcortical brain segmentation. Neuroimage. 2011 Jun;56(3):907-22.

23 Stein JL, Medland SE, Vasquez AA, Hibar DP, Senstad RE, Winkler AM, et al.; Alzheimer's Disease Neuroimaging Initiative; EPIGEN Consortium; IMAGEN Consortium; Saguenay Youth Study Group; Cohorts for Heart and Aging Research in Genomic Epidemiology Consortium; Enhancing Neuro Imaging Genetics through Meta-Analysis Consortium. Identification of common variants associated with human hippocampal and intracranial volumes. Nat Genet. 2012 Apr; 44(5):552-61.

24 Zhang Y, Brady M, Smith S. Segmentation of brain MR images through a hidden Markov random field model and the expectationmaximization algorithm. IEEE Trans Med Imaging. 2001 Jan;20(1):45-57.

25 Glickman ME, Rao SR, Schultz MR. False discovery rate control is a recommended alternative to Bonferroni-type adjustments in health studies. J Clin Epidemiol. 2014 Aug;67(8): $850-7$.

26 Benjamini Y, Hochberg Y. Controlling the false discovery rate: A practical and powerful approach to multiple testing. J R Stat Soc B. 1995;57(1):289-300.

27 Welty TK, Lee ET, Yeh J, Cowan LD, Go O, Fabsitz RR, et al. Cardiovascular disease risk factors among American Indians. The Strong Heart Study. Am J Epidemiol. 1995 Aug; 142(3):269-87.

28 Lee ET, Cowan LD, Welty TK, Sievers M, Howard WJ, Oopik A, et al. All-cause mortality and cardiovascular disease mortality in three American Indian populations, aged 4574 years, 1984-1988. The Strong Heart Study. Am J Epidemiol. 1998 Jun;147(11):995-1008.

29 Bokura H, Yamaguchi S, Iijima K, Nagai A, Oguro H. Metabolic syndrome is associated with silent ischemic brain lesions. Stroke. 2008 May;39(5):1607-9.

30 Park K, Yasuda N, Toyonaga S, Tsubosaki E, Nakabayashi H, Shimizu K. Significant asso- ciations of metabolic syndrome and its components with silent lacunar infarction in middle aged subjects. J Neurol Neurosurg Psychiatry. 2008 Jun;79(6):719-21.

31 Kwon HM, Kim BJ, Lee SH, Choi SH, Oh BH, Yoon BW. Metabolic syndrome as an independent risk factor of silent brain infarction in healthy people. Stroke. 2006 Feb;37(2): 466-70.

32 Howard G, Wagenknecht LE, Cai J, Cooper L, Kraut MA, Toole JF. Cigarette smoking and other risk factors for silent cerebral infarction in the general population. Stroke. 1998 May; 29(5):913-7.

33 Aono Y, Ohkubo T, Kikuya M, Hara A, Kondo T, Obara T, et al. Plasma fibrinogen, ambulatory blood pressure, and silent cerebrovascular lesions: the Ohasama study. Arterioscler Thromb Vasc Biol. 2007 Apr;27(4): 963-8.

34 Walther K, Birdsill AC, Glisky EL, Ryan L. Structural brain differences and cognitive functioning related to body mass index in older females. Hum Brain Mapp. 2010 Jul;31(7): 1052-64.

35 Driscoll I, Gaussoin SA, Wassertheil-Smoller S, Limacher M, Casanova R, Yaffe K, et al. Obesity and Structural Brain Integrity in Older Women: The Women's Health Initiative Magnetic Resonance Imaging Study. J Gerontol A Biol Sci Med Sci. 2016 Mar;71(9):1216-1222.

36 Windham BG, Lirette ST, Fornage M, Benjamin EJ, Parker KG, Turner ST, et al. Associations of Brain Structure With Adiposity and Changes in Adiposity in a Middle-Aged and Older Biracial Population. J Gerontol A Biol Sci Med Sci. 2017 Jun 1;72(6):825-31.

37 Barrett-Connor E, Edelstein SL, CoreyBloom J, Wiederholt WC. Weight loss precedes dementia in community-dwelling older adults. J Am Geriatr Soc. 1996 Oct;44(10): 1147-52.

38 Willette AA, Bendlin BB, McLaren DG, Canu E, Kastman EK, Kosmatka KJ, et al. Age-related changes in neural volume and microstructure associated with interleukin- 6 are ameliorated by a calorie-restricted diet in old rhesus monkeys. Neuroimage. 2010 Jul;51(3):987-94.

39 Guzzardi MA, Iozzo P. Brain functional imaging in obese and diabetic patients. Acta Diabetol. 2019 Feb;56(2):135-44.

40 Abbott PJ. Screening American Indian/Alaska natives for alcohol abuse and dependence in medical settings. Curr Drug Abuse Rev. 2011 Dec;4(4):210-4.
41 Patterson Silver Wolf Adelv Unegv Waya DA, Duran B, Dulmus CN, Manning AR. Alcohol Screening and Brief Intervention as Standard Practice: Working with the American Indian/ Native Alaskan Populations. J Hum Behav Soc Environ. 2014 Mar;24(3):399-407.

42 Spicer P, Beals J, Croy CD, Mitchell CM, Novins DK, Moore L, et al.; American Indian Service Utilization, Psychiatric Epidemiology, Risk and Protective Factors Project Team. The prevalence of DSM-III-R alcohol dependence in two American Indian populations. Alcohol Clin Exp Res. 2003 Nov;27(11):178597.

43 Ding J, Eigenbrodt ML, Mosley TH Jr, Hutchinson RG, Folsom AR, Harris TB, et al. Alcohol intake and cerebral abnormalities on magnetic resonance imaging in a community-based population of middle-aged adults: the Atherosclerosis Risk in Communities (ARIC) study. Stroke. 2004 Jan;35(1): 16-21.

44 Anstey KJ, Jorm AF, Réglade-Meslin C Maller J, Kumar R, von Sanden C, et al. Weekly alcohol consumption, brain atrophy, and white matter hyperintensities in a community-based sample aged 60 to 64 years. Psychosom Med. 2006 Sep-Oct;68(5):778-85.

45 Zahr NM, Mayer D, Rohlfing T, Orduna J, Luong R, Sullivan EV, et al. A mechanism of rapidly reversible cerebral ventricular enlargement independent of tissue atrophy. Neuropsychopharmacology. 2013 May;38(6):1121-9.

46 Schweigman K, Eichner J, Welty TK, Zhang Y. Cardiovascular disease risk factor awareness in American Indian communities: the strong heart study. Ethn Dis. 2006;16(3):647-52.

47 Duriez Q, Crivello F, Mazoyer B. Sex-related and tissue-specific effects of tobacco smoking on brain atrophy: assessment in a large longitudinal cohort of healthy elderly. Front Aging Neurosci. 2014 Nov;6:299.

48 Gallinat J, Meisenzahl E, Jacobsen LK, Kalus P, Bierbrauer J, Kienast T, et al. Smoking and structural brain deficits: a volumetric MR investigation. Eur J Neurosci. 2006 Sep;24(6): 1744-50.

49 Peng P, Wang Z, Jiang T, Chu S, Wang S, Xiao D. Brain-volume changes in young and middle-aged smokers: a DARTEL-based voxelbased morphometry study. Clin Respir J. 2017 Sep;11(5):621-31.

50 Markman SE, Phillips CD, Caldwell SH. Reversibility of alcohol-related brain atrophy. Liver Transpl. 2000 May;6(3):370-1. 